\title{
The Problem of Stuttering: Where are we in $1986 ?^{*}$
}

\author{
Hugo H. Gregory, Ph.D (Northwestern University, USA) \\ Department of Communication Disorders, \\ Northwestern University, Illinois, USA
}

\begin{abstract}
The paper revies the author's experience as a person with a stuttering problem, as a student and as a professional clinician, teacher and researcher. An overview of the state of the art in 1986 is presented
\end{abstract}

\section{OPSOMMING}

Die artikel verskaf' $n$ oorsig van die outeur se ondervinding as ' $n$ hakkelaar, as 'n student en as ' $n$ terapeut, leermeester en navorser op die gebied van hakkel. Die stand van die teorie en die kliniese praktyk in 1986 word beskryf.

My review and analysis, leading to statements about the current status of our knowledge of stuttering, begins over 40 years ago when a blond, fourteen year old boy from the state of Arkansas in the USA journeyed 1500 miles to the state of Rhode Island to get help with his stuttering problem. That summer at an institution known as Martin Hall, I learned that stuttering was due to a faulty reaudiorization and revisualization of words and developed fears of speaking. Therapy consisted of being on silence (no conversation) for periods of time in which we practised syllables, words and sentences from a drill manual. We learned a rule for the production of each consonant, and as we said a syllable or word, we thought of the rule for each consonant and called up strong auditory and visual images. This first step was known as word analysis. I analyzed words all over that beautiful landscape on Mount Hope Bay in Rhode Island. In word analysis, transitions between sounds were very smooth, but words were spoken one at a time. At the end of two weeks, we came off a silence for the weekend and were allowed to speak, using careful word analysis. To a girl, to whom I had been writing notes while on silence, I was now able to say, "P-A-T, W-O-U-L-D Y-O-U L-I-K-E T-O G-O T-O T-H-E M-O-V-I-E S-A-T-U-R-D-A-Y N-I-G-H-T?" After that weekend we went back on silence to practise phrasing in which we analyzed only the first word of the phrase. At the end of two more weeks, I was able to say, "Pat/ would you like to go / to the Biltmore Hotel / in Providence / for dinner / Saturday night?". In addition to the improvement in speech, the jump up in two weeks from a movie in Bristol to dinner at the Biltmore in Providence was pretty exciting. Not bad for a 14 year old!

This was my first introduction to what we now designate as the speak-more-fluently approach to therapy. I viewed word analysis and phrasing as the way to break the habit of stuttering and to learn to speak fluently. I hoped to substitute word analysis and phrasing for stuttering.

Although I was conscientious in practising words and sentences every day, utilizing my rules, a few months after I returned home I began to slip, to have increasingly more trouble. However, I never had as much difficulty again as before that first summer of therapy. Today, we would say that I did not have an adequate transfer and maintenance experience. During this period, I gained a greater appreciation of the fear component of stuttering, as I perceived the way in which my apprehension about speaking reappeared.

When I returned to the program the following summer, I began to realize that I had concentrated on the speech aspect of therapy and was missing a great deal of the part having to do with attitude. I recalled that the clinicians had talked about the way in which stutterers, in fact all people, tend to overemphasize what they perceive as a problem. For example, stutterers tend to become very sensitive about the fluency of their speech. In examining my attitude, I began to see that if I stuttered in a situation, I was very hard on myself. I considered myself pretty much of a failure. Later on, after I was in college, Wendell Johnson's ideal helped me to understand that I should not attempt to evaluate myself as "either or", i.e. either I am a stutterer or I am not a stutterer. Therefore I began to view myself more and more as a person who stuttered sometimes as he talked, and I realized that I was going through a process of changing.

In 1949, I went to Northwestern to study "speech correction". I learned about many theories of stuttering with the most focus on the ideas of Charles Van Riper and Wendell Johnson. Van Riper spoke of predisposing factors, precipitating factors, and maintaining factors. Predisposing factors could be physiological. Johnson emphasized that the misevaluation of children's disfluency by parents and others led to an apprehensive, anticipatory, hypertensive, avoidance reaction. This led to the learning of stuttering.

I had some great experiences. I met and talked with Wendell Johnson and Lee Edward Travis at the 1950 convention of the American Speech and Hearing Association attended by only 400 people. I had some not-so-great experiences too. I met a gentleman at that convention who asked me what I had learned about stuttering at Northwestern, and so I told about Bryngelson, Johnson, Sheehan, Travis, Van Riper, etc. He asked if I had heard of Isaac Karlin's delayed mylinization theory; and after I said I had not, he told me, "I am Isaac Karlin." Of course, I reviewed Van Riper's text and found out about Dr. Karlin and wrote to tell him I now knew about his theory. Well, you live and learn!

*This paper is a written version of the $P$ de V Pienaar Memorial Lecture delivered on 16 July 1986 at the University of the Witwatersrand. 
At that 1950 convention of ASHÄ, John Black from Ohio State and Grant Fairbanks of the University of Illinois demonstrated delayed auditory feedback (DAF) equipment and the effect of $D A F$ on speech. One of my professors introduced me to them and I spoke under DAF. Apparently I did better than most people, i.e. DAF did not distrub my speech flow as much as Black and Fairbanks expected. They concluded that this was due to my concentrating on tactile-kinesthetic monitoring as I spoke, one thing I had learned to do in therapy. As the 1950 s moved along, several studies including my own doctoral dissertation, looked at auditory processes in stutterers, research that has continued until the present time. Findings of a problem in the auditory system have not been conclusive.

In the decade and one-half from 1960 to 1975 , there was a great emphasis on studying stuttering as learned behaviour. Actually, the foundation for this work was laid by Wischner's reasoning, relating learning theory concepts to Johnson's diagnosogenic explanation of the development of stuttering, and by Sheehan's writing about stuttering as an approach avoidance conflict. From Sheehan and Wischner, I learned that the momentary reduction of anxiety and tension that follows the occurrence of stuttering probably reinforces unadaptive stuttering behaviour (Sheehan, 1953; Wischner, 1950). Since we were so focused upon the punishing nature of stuttering, it was difficult to comprehend how the occurrence of stuttering could be rewarding or reinforcing in this way.

In my first university teaching position at Southern Illinois University, from 1958-1962, I had two colleagues, Israel Goldiamond and Eugene Brutten, both of whom were to become well known for their research relating learning concepts to stuttering. Flanagan, Goldiamond, and Azrin (1958) investigated the possibility that stuttering was an operant behaviour by presenting bursts of a loud noise contingent upon moments of stuttering. This contingency resulted in decreases of stuttering in 3 subjects. Later they presented five seconds of DAF contingent upon stuttering with the same results. They began to conclude that stuttering responded like an operant behaviour as defined by Skinner (1953). Flanagan related to me that one day while he went to get coffee, he left the DAF on continuously, and on his return, he found a stutterer speaking without stuttering in a prolonged speech pattern. Thus, the use of DAF in therapy was born.

After many more studies showing that the effects of assumed positive, negative and neutral verbal response contingencies ("right", "wrong", "tree") and time-out were all equally as effective in reducing stuttering, it was assumed that the best explanation was that all of these contingencies highlighted stuttering. Highlighting, it was said (Siegel, 1970) may result in an increase of the aversive properties of cognitive and response produced stimuli; thus, these responses could serve to punish the behaviour. Maybe in this way, stuttering did follow the rules of operant behaviour.

Meanwhile, returning to my sequential story, my other colleague at Southern Illinois University, Gene Brutten, had teamed up with Don Shoemaker to offer us a two-factor theory of stuttering (Brutten and Shoemaker, 1967). Their concept was that fluency, the predominant characteristic of normal speech, is disrupted by learned classically conditioned negative emotionality that increases fluency failures (repetitions and prolongations). Unadaptive instrumental behaviours or operant responses, known commonly as secondary reactions, that reduce emotional responses are reinforced, adding to the complexity of fluency failure.

A very important observation to be made of conditioning studies was that not all subjects responded in the same way. Again, we saw that stuttering could not be simplified. In addition to emotional variables and overt behavioural variables, complex cognitive variables probably also influence stuttering behaviour. Designing research to deal with all of these influences is compli-
cated and requires much more work.

As for the application of learning concepts, Hobart Mowrer, the great American psychologist, assured me that we speech-languagc pathologists had always been the quintessence of behaviourists. During the period I am now discussing, we clinicians, influenced by the behaviourists of our times, gave more specific attention to target responses, instructions, modelling, reinforcement, and the programming of change. We became more definitive in measuring behaviour and recording quantity of change in our reports. I never thought we could measure objectively all of the dimensions of change with which we deal, but we measured what we could, and our goal has been to strive for better approaches to assessment.

Meanwhile, Kidd and his associates (Kidd, 1980), and even Sheehan (Sheehan and Costley, 1977), were becoming more convinced that there is a genetic factor in stuttering, a postulation that has been around for a long time. At the same time, all of us were recognizing the higher incidence of other speech and language problems in children who stutter (an observation first made by Mildred Berry [1938]). Perhaps, it is the motolinguistic developmental factors that are inherited. Finally, a book clarifying the present status of our knowledge about the genetic aspects of speech and language disorders has been written (Ludlow and Cooper, 1983).

More recently, the findings of brain hemispheric functioning differences with reference to alpha suppression when anticipating expressive speech has brought forth considerable discussion. Stutterers show more alpha suppression (representing greater activity) in the right hemisphere on verbal tasks; whereas nonstutterers show more in the left hemisphere (Moore, 1984). This difference reminds us of the differences in auditory dichotic listening (using meaningful words) in which stutterers show more reversals and smaller between ear difference scores (Gregory and Mangan, 1982). Remember, these are group results and do not mean that all stutterers respond in one way or another. Finally, the recent findings that a group of adult stutterers who showed more right hemisphere alpha suppression before therapy, shifted to more left hemisphere suppression following therapy is intriguing. The therapy program emphasized the temporalsegmental aspects of speech, and possibly this treatment is mirrored by brain functioning (Boberg, Yendall, Schopflocher and BoLassen, 1983). That is the way it should be.

Although findings are somewhat mixed, the motor speech reaction time differences in which stutterers show slower voice initiation times implies a slower reacting motor system in stutterers. One study of this in children (Cullinan and Springer, 1980) showed that stuttering children with other language and learning problems showed the motor reaction time differences, others did not. But, there is still debate about the influence of emotional conditioning on the small differences found.

Here we are in 1986. The blond boy of earlier years turned grey early as he grappled with the problem of stuttering. Up to this point in this paper I have traced my experience as a person with a stuttering problem, as a student, and as a professional clinician, teacher, and researcher. At this point in my development, where do I think we are? 
. We know more about the disfluency of children's speech and . the quantity and quality of disfluency - including such characthe quantily and quber of repetitions per instance of part-word, or teristics as the num disfluency. Perhaps new information from one-syllable-word distectro-glottography (Conture, 1984) will procedures such as elect to the decision making process. If provide additional input to the we would see that we have Wendell Johnson were living to complexities of added significantly to children's disfluencies.

2. Sometimes in the future we may be precise in stating the cause . or caus subject and environmental variables that appear to be associated with stuttering and about how the manipulation of these factors decreases stuttering. We must constantly question we are applying the knowledge we have as effectively as whether we colleagues and I are continuing to refine our propossible. My coflential evaluation - differential theory. We are cedures for differention on adults as well as children. At present, fore specificity in this regard about children, who are nearer to the age of onset, than there is for adults.

3. We have gained a better understanding of motor and linguistic factors associated with stuttering and about how to manage those factors as an integral part of therapy. Many stuttering children appear to have marginal capacities for speech production. The demand for communication has to be controlled carefully.

With references to research findings that there are minimal motoric differences of the speech mechanism (slowness of vocal reaction time and longer voice onset times [VOT] or measurably longer glottal adduction per glottal cycle in some children who stutter), it would seem appropriate to utilize procedures that provide a vivid model for the child and that usually involve the slowing of speech production and a smoother blending of speech sound transitions. On the other hand, if we are only dealing with maladaptive learning, these modifications of speech production are still appropriate. Possibly, we should consider giving stutterers practice in the rapid initiation and termination of vowels and consonant-vowel combinations. Assuming that the fluency of speech is related to these basic skills, particularly when children are experiencing linguistic or environmental stress, it could be important to improve these skills.

4. Progress has been made in assêssing parent-child interaction factors more objectively using standardized observation procedures. Recent work by Meyers and Freeman $(1985 a, b)$ on parental interruptions of disfluent childreñ is important in this regard. Parallel to this we are counselling parents more effectively by employing not only verbal counselling, but by modelling changes for them. I first wrote about this in 1973 , and we have continued to refine procedures over the years for changing parental behaviour, as well as the child's behaviour.

5. In the past 15 years, research and clinical experience in behaviour-analysis behaviour-modification has enabled us to be more effective and efficient in changing the behaviour of children who are beginning to stutter, their parents, and more confirmed stutterers. We are more systematic in the manipulation of stimulus variables including consequences for unadaptive and adaptive behaviour. But the planned use of modelling, clinicians seeing the importance of their role as a model, has been one of the most significant developments in behaviour change procedures. Behaviour modification is viewed to include making up for deficit behaviours such as sound sequencing and word finding, assertive behaviour, and social skills.
6. The controversy between the advocates of stutter-more-fluently and speak-more-fluently models has been clarified and many clinicians are now integrating the two. For example, we begin with adult stutterers by monitoring unadaptive stuttering behaviour, stuttering with less tension; and then, through relaxed speech onsets, phrasing, etc. stutterers learn behaviour that is counter to stuttering. A major advantage of combining the two models is that stutterers learn to cope with moments of stuttering, resulting in reduced sensitivity about stuttering and diminished fear of regression or relapse, but they also learn improved speech skills and flexibility in speaking.

7. During the last ten years we have faced up to the definite need for planned transfer and maintenance activities that include making speech production spontaneous and natural. In this connection, in building fluency I always attempt to distort natural prosody as little as possible. I now say that the person, child or adult, has to continue therapy on a less intensive basis, with less and less self-monitoring, for 12-18 months following the core period of therapy (whether it is one month, six months, or whatever), until speech is more spontaneous and normally fluent, and self-confidence to handle variations in fluency and disfluency is sufficient.

8. Attitude change remains a controversial area. Valid measurement is a paramount issue. Possibly a new scale being standardized by Jenifer Barber Watson that taps behavioural, cognitive, and affective factors and that stresses a comparison of these components will be useful. All clinicians influence attitudes. Some see direct work on cognitive and affective components as important. Others see behaviour change as the most effective approach to attitude change. Although subjective, I believe we need to explore beliefs and feelings as verbalized, or demonstrated in behaviour, to help clients clarify their attitudes and see the relation between their attitude and their behaviour.

9. Increased measurement of stuttering behaviour, and here we still have a problem of definition, has resulted in more efficient still have a prective therapy. Criteria for stuttering differ somewhat, but one syllable word repetition, part-word sound and syllable repetition, prolongations, combinations of these behaviours, and unique vocal tract disruptions characteristic of individual stutterers are counted as stuttering. Extratherapy measurements involve problems. Overt and covert measures, according to Howie, Woods and Andrews (1982), appear to differ the most immediately following treatment. Ingham (1984) has provided a model for a time-series of assessments before, during, and following therapy.

10. Clinicians are becoming more able to adapt procedures, generate their own approaches, and treat stutterers as the individuals they are.

11. Finally, we must improve the training of clinicians. More clinicians are specializing in stuttering therapy. In the summer of 1985 , we had a two-week workshop for specialists who already had from one to twenty years of experience. I would be pleased to see the certification of specialists so that the public could identify those who are more competent in the evaluation and treatment of stutterers. 


\section{Aids for}

- the development of perception

- the acquisition of speech and language skills

- the improvement of motor co-ordination

\section{Plus}

- helpful texts for therapists

- educational toys, books and equipment

- records for auditory training

- catalogues on request

- large variety of tests available

\section{Stockists of}

- Learning to Listen

- Two sound lottos

- Full LDA range

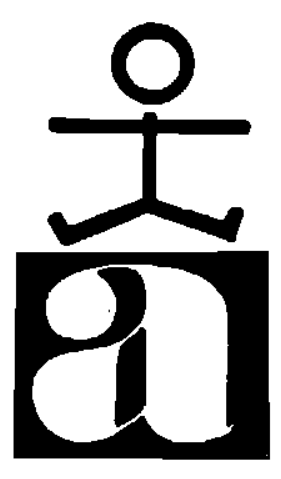

\section{PLAY AND SCHOOLROOM}

44 President Place,

148 Jan Smuts Ave., Rosebank.

Telephone 788-1304

P.O. Box 47288, Parklands 2121. 
The Problem of Stuttering (Continued from Page 5)

\section{REFERENCES}

Berry, M. Developmental history of stuttering children. J. Ped., 12: 209-217 1938 .

Brutten, E. and Shoemaker, D. The modification of stuttering. New Jersey, Prentice-Hall, 1967.

Boberg, E., Yendall, L., Schopflocher, D., Bo-Lassen, P. The effects of an intensive behavioural program on the distribution of EEG alpha power in stutterers during the processing of verbal and visuospatial information. J. Fluency Dis., 8, 245$263,1983$.

Conture, E. Observing laryngeal movements of stutterers. In Curlee, W. and Perkins, W.H. (eds). Nature and treatment of stuttering. San Diego: College-Hill, 1984.

Cullinan, W. and Springer, M. Voice initiation and termination times in stuttering and nonstuttering children. J. Speech Hear. Res., 23, 344-361, 1980.

Flannagan, B., Goldiamond, I. and Azrin, N. Operant stutterin The control of stuttering behaviour through response contingent consequences. J. Experimental Analysis of Behav., 1, 173-177, 1958.

Gregory, H. and Mangan, J. Auditory processes in statterers. In Lass, N. (ed) Speech and Language Advances in basic research and practice. Volume 7. New York: Academic Press, 1982. mediately after stuttering treatment. J. Speech Hear. Disorders, 47, 419-422, 1982.

Ingham, $\mathbf{R}$. Toward a therapy assessment procedure for treating stuttering in children. In Gregory, H.H. (ed). Stussering therapy: Prevention and intervention with children. Memphis: Speech Foundation of America, 1984.

Kidd, K. Genetic Models of stuttering. J. Fluency Dis., 5, 187-201, 1980.

Ludlow, C. and Cooper, J. Genetic aspects of speech and language. New York: Academic Press, 1983.

Meyer, S. and Freeman, F. Interruptions as a variable in stuttering and disfluency. J. Speech Hear. Res., 28, 428-435, 1985a.

Meyers, S. and Freeman, F. Mother and child speech rates as a variable in stuttering and disfluency. J. Speech Hear. Res., 28, 436-444, 1985 b.

Moore, W.H. Central nervous system characteristics of stutterers. In Curlee, W. and Perkins, W.H. (eds). The nature and treatment of stuttering. San Diego: College-Hill Press.

Sheehan, J.G. Theory and treatment of stuttering as an approachavoidance conflict. Journal of Psychology, 36, 27-49, 1953.

Sheehan, J.G. and Costle, M. A reexamination of the role of heredity in stuttering. J. Speech Hear. Dis., 42, 47-59, 1977.

Siegel, G.M. Punishment, stuttering and disfluency. J. Speech Hear. Res., 13, 677-714, 1970.

Skinner, B. The sciences of human behaviour. New York: Appleton-Century-Crofts, 1953.

Wischner, G.J. Stuttering behaviour and learning: A preliminary 